\title{
DOMAIN-SPECIFIC MARKUP LANGUAGES AND DESCRIPTIVE METADATA: their functions in scientific resource discovery
}

\section{LINGUAGENS DE MARCAÇÃO ESPECÍFICAS POR DOMÍNIO E METADADOS DESCRITIVOS: funções para a descoberta de recursos científicos}

\author{
Marcia Lei Zeng \\ School of Library and Information Science, \\ Kent State University, Kent, Ohio, USA \\ mzeng@kent.edu
}

\begin{abstract}
While metadata has been a strong focus within information professionals' publications, projects, and initiatives during the last two decades, a significant number of domain-specific markup languages have also been developing on a parallel path at the same rate as metadata standards; yet, they do not receive comparable attention. This essay discusses the functions of these two kinds of approaches in scientific resource discovery and points out their potential complementary roles through appropriate interoperability approaches.
\end{abstract}

KEYWORDS: Metadata. Markup languages. Scientific resource.

\section{METADATA STANDARDS AND DOMAIN-SPECIFIC MARKUP LANGUAGES DEVELOPMENT}

Metadata is "structured information that describes, explains, locates, or otherwise makes it easier to retrieve, use, or manage an information resource" (NISO, 2004) ${ }^{1}$. Many metadata standards have been created by a variety of communities. Examples include:

a) Metadata standards applicable for many subject areas and resources:

- Dublin Core Metadata Element Set (DCMES)

- Dublin Core Metadata Terms

- Electronic Theses and Dissertations Metadata Standard (ETD-MS)

- Learning Object Metadata (LOM)

- Metadata Object Description Schema (MODS)

b) Metadata standards in scientific areas:

- ADN (ADEPT/DLESE/NASA) Metadata Framework - for the Earth system education community

- Content Standards for Digital Geospatial Metadata (CSDGM)

- Darwin Core - a standard for describing objects contained within natural history specimen collections and species observation databases

- ISO/TS 19115:2003 Geographic information - Metadata

During the evolution of our digital age, XML (Extensible Markup Language) - developed by an XML Working Group formed under the auspices of the World Wide Web Consortium

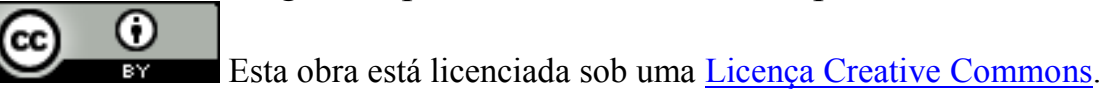

DOI 10.5007/1518-2924.2010v15nesp2p164

${ }^{1}$ NISO. Understanding Metadata. Bethesda, MD: NISO Press. http://www.niso.org/standards/resources/UnderstandingMetadata.pdf.
Enc. Bibli: R. Eletr. Bibliotecon. Ci. Inf., Florianópolis, n. esp., $2^{\mathbf{o}}$ sem. 2010. ISSNe 1518-2924. 
(W3C) in 1996 (continuously amended) - has become the official metalanguage for many communities. Simply speaking, XML "describes a class of data objects called XML documents and partially describes the behavior of computer programs which process them"2. Markup encodes a description of the document's storage layout and logical structure. XML provides a mechanism to impose constraints on the storage layout and logical structure. The W3C does not create domain-based markup languages, instead leaving that to the appropriate creators in each domain. Thus domain-specific markup languages have also been developed by various communities, particularly in scientific areas. For example:

a) High level domain-specific markup languages:

- MathML (Mathematical Markup Language) - containing two sets of tags: one for presentation of formulas; and another, for the meaning of mathematical expressions. It provides a foundation for the inclusion of mathematical expressions in Web-based publications.

- GML (Geography Markup Language) - an XML grammar for expressing geographical features

- CML (Chemical Markup Language) - concentrating on "molecules" (discrete entities representatable by a formula and usually a connection table), it supports a hierarchy for compound molecules, reactions, and macromolecular structures/sequences.

- MatML (eXtensible Markup Language for Materials Property Data)

- MML (Medical Markup Language)

- $\quad$ And more]

b) More specialized markup languages or application profiles further extend the high level domain markup languages. Using GML as an example, over two dozen standards have been developed or are in development:

- GML (Geography Markup Language):

$\checkmark$ TWML (Tsunami Warning Markup Language) - A Standards-based Language for Tsunami Bulletins

$\checkmark$ Canadian Road Markup Language (for Road Network File)

$\checkmark$ CityGML

$\checkmark$ CWML (Cyclone Warning Markup Language)

$\checkmark$ dwGML (Digital Weather Geography Markup Language)

$\checkmark$ GDF-GML (Geographic Data Files)

$\checkmark$ GML 3.1.1 Application schema for Earth observation products

$\checkmark$ GPlates Markup Language (representing geological data in a plate tectonics context)

$\checkmark$ SoTerML (Soil and Terrain Markup Language)

$\checkmark$ [And roughly twenty more] $^{3}$

Figure 1 illustrates the relationships of metalanguages and specific markup languages that are developed for particular types of resources or for particular subject domains.

${ }^{2}$ Extensible Markup Language (XML) 1.0 (Fifth Edition), W3C Recommendation 26 November 2008. http://www.w3.org/TR/REC-xml/. 


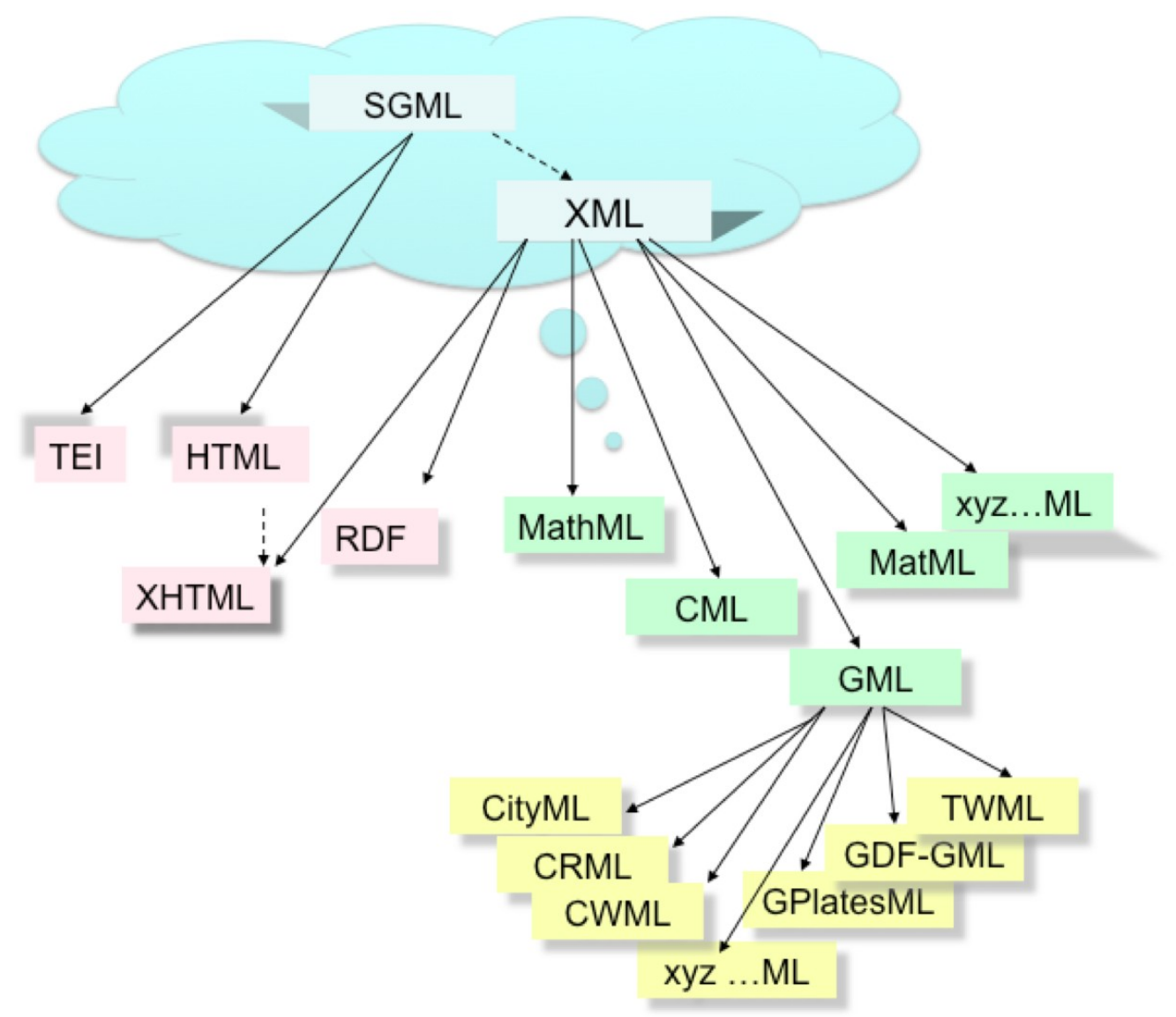

Figure 1 - Metalanguage and Specific Markup Languages (a representative list).

Source: Created by the author.

The growth of both metadata standards and domain-specific markup languages in scientific areas has reflected the great need of more standardized and structured data representation for discovery purposes. They are developed for specific discovery purposes.

\section{ENHANCING THE DISCOVERY FUNCTION THROUGH STRUCTURE- AND CONTENT-DECOMPOSITION}

Whether metadata standards or markup language standards, all methodologies strive to effectively describe information resources for the purpose of discovery. If we look into the information resources themselves, what is to be discovered may be at different atomic levels. Most information resources (e.g., a database, a dissertation, an article, or a handbook) can best be understood as information containers that have internal structures that are of interest to information users. Digital collections and digital repositories have mainly utilized the information container level of description in order to organize, access, use and reuse scientific knowledge. Differences reside in some distinct digital collections and repositories that have greater granularity of some containers than others.

The concept of 'decomposition' was first brought up and tested in the Green's Functions Research and Education Enhancement Network (GREEN) project chaired by Dr. Greg Shreve at Kent State University Applied Linguistics Institute (where the author was also a Co-P.I.). Green's Functions is a broadly used analytic technique that is applicable across many applications and disciplines and is used to study a wide spectrum of different phenomena, 
ranging from subsidence in gas and oil reservoirs to thermo-elastic deformation in silicon chips $^{4}$ (SHREVE; ZENG, 2003). The GREEN project was one of the National Science Foundation (NSF) National Science, Mathematics, Engineering, and Technology Education Digital Library (NSDL) projects during 2001 and 2004. The discussions in this article are based on the GREEN project initiations ${ }^{5}$ (SHREVE; ZENG, 2003) while also representing deeper methodological and functional explorations of metadata and markup languages.

\subsection{Structure decomposition}

In order to reveal the rich contents of a resource, usually the first attempt is to describe the structural components at a greater granular level. In a structured data record, for example, components would consist of detailed elements: title, abstract or table-of-contents, index, references, contained images, illustrations, tables, glossary, and so on. Metadata standards commonly denote specific elements for some of the components. The following examples are from the DCMI Metadata Terms; therefore their prefix is either " $\mathrm{dt}$ " (the qname for the legacy DC-15 namespace) or "dct" (for the DCMI Terms namespace which also includes DC-15 elements). These elements are "dc:title", "dct:abstract", "dct:bibliographicCitation", "dct:references", and "dct:tableOfContents". Other metadata standards have similar methods to decompose structures. An arbitrary approach is to break down these components and treat them as individual resources with individual metadata descriptions. For example, we can create a record for each important chapter of a dissertation in addition to a record for the whole dissertation. The components are linked to the whole through a "relation" element (e.g., "dct:hasPart" and "dct:isPartOf"). With this approach, metadata is well-suited to handle the tasks of describing the components, while presenting structural (instead of semantic) relationships between or among them.

\subsection{Content decomposition}

Another attempt is to disclose the topic(s) that an information resource discusses or things it depicts through the decomposition of the content of a resource. For this, metadata and markup languages have differing levels of effectiveness.

\subsubsection{Enriched 'subject' metadata}

A universal element of almost all metadata standards is "subject". Other subject-related elements are included more or less in these standards, such as (with the prefix denoting their namespace) "dct:spatial", "dct:temporal", "vra:culturalContext", "vra:stylePeriod", "vra:material", "lom:taxon", "lom:keywords", "lom:purpose", and so on.

Metadata application profiles and new schemas developed based on general metadata standards may add more requirements to increase and ensure the domain-specific subject elements. Take an example from the National Library of Medicine (NLM) Metadata Schema: "dc:subject" is extended to "DC.Subject.MeSH" and "NLMDC.Subject.NLMClass". MeSH (Medical Subject Headings) and NLM Classifications contain highly specific concepts and classes of concepts. The dedicated metadata elements will enable consistent and systematic access to the resources in medical and related subject areas.

4 SHREVE, Gregory M.; ZENG, Marcia Lei. Integrating Resource Metadata and Domain Markup in an NSDL Collection. In: DC-2003: Proceedings of the International DCMI Metadata Conference and Workshop, Sep. 28-Oct. 2, 2003, Seattle, Washington: p. $223-229$. Disponível em: http://www.siderean.com/dc2003/604_paper62.pdf.

5 Ibid.

Enc. Bibli: R. Eletr. Bibliotecon. Ci. Inf., Florianópolis, n. esp., 2º sem. 2010. ISSNe 1518-2924. 
However, there are two issues with such practices: 1) subject-related metadata elements are quite restricted in metadata element sets; 2) for a 'container', a metadata instance is always in the position of a surrogate. Taking the example of a dissertation in materials science: even if a metadata record provides detailed subject-related access, e.g., ten specific keywords which supply names of the materials or issues discussed in it, it only satisfies the task of 'pointing out the direction' in a discovery effort. The structure-decomposition approach mentioned previously may bring better subject access because different topics of each chapter in the dissertation are surfaced when the chapter has an individual descriptive metadata record. Still, the metadata description is for the container.

\subsubsection{Highly-enumerative, domain-oriented metadata}

Metadata schemas or application profiles aiming at scientific areas have been extending their elements beyond a "container" description and emphasizing specific subject-domain-oriented description. Here we can use two standards to demonstrate such trends. Note that in the remaining text, categories of elements are included in the curly brackets $\{\ldots\}$ and elements are in quotation marks "container".

The ADN Framework ${ }^{6}$ is built on the specifications and best practices of the Alexandria Digital Earth Prototype (ADEPT) project, the Digital Library for Earth System Education (DLESE), (NASA) Joined Digital Library. Among the nine categories (\{Administration\}, \{Creator-cataloger\}, \{Educational\}, \{General\}, \{Geospatial\}, \{Relation\}, \{Rights\}, $\{$ Technical $\}$, and $\{$ Temporal $\}$ ) the $\{$ Geospatial\} category is the one most specifically designed for the discovery purpose. "Experts in library science, software engineering and geoscience from the Alexandria Digital Library, the Colorado School of Mines and the DLESE Program Center participated in the development of the framework's geospatial concepts over an 18 month period"7 (ADN FRAMEWORK, 2003). The elements captured from this $\{$ Geospatial\} category form an impressive list: "Overarching bounding box", "Detailed geometries", "Elevation", "Planet or body", "Place-name tied to coordinates", "Place-name not tied to coordinates", "Event name tied to coordinates", "Event name not tied to coordinates", "Objects in space", "Coordinate system", "Vertical and horizontal datum", "Projection", and "Latitudes and longitudes". For educational materials, and especially when granularity is at a great level, this metadata framework seems to have functioned successfully at the DLESE digital library (a geoscience community resource that supports teaching and learning about the Earth system).

The second example is the Darwin Core metadata terms. Darwin Core presents its metadata terms (i.e., elements) in nine major categories: \{Record-level Terms\}, \{Occurrence\}, \{Event\}, \{Location\}, \{GeologicalContext\}, \{Identification\}, \{Taxon\}, \{ResourceRelationship\}, and \{MeasurementOrFact\}. More than one hundred metadata terms contribute to its schema; for example: \{Event\} - 15 terms; \{dcterms:Location\}-40+ terms; \{geologicalContextID\} - 18 terms; and, \{MeasurementOrFact\}-9 terms. What a category includes are very specific elements that are to be used to describe many characteristics of the contents in a resource. Taking the \{Taxon\} category, some terms are for labels ("scientificName", "acceptedNameUsage", "parentNameUsage”, “originalNameUsage", "nameAccordingTo", "namePublishedIn", "vernacularName", "nomenclaturalCode", etc.) and some are for taxonomy ("higherClassification", "kingdom", "phylum", "class", "order", "family", "genus", "subgenus", "specificEpithet", “infraspecificEpithet", "taxonRank",

\footnotetext{
${ }^{6}$ ADN Framework. http://www.dlese.org/Metadata/adn-item/index.php.

ADN Framework Geospatial Overview, 2003, http://www.dlese.org/Metadata/adn-item/geospatial.php.

Enc. Bibli: R. Eletr. Bibliotecon. Ci. Inf., Florianópolis, n. esp., $2^{\circ}$ sem. 2010. ISSNe 1518-2924.
} 
"verbatimTaxonRank", etc.) This standard has already been successfully used as the base of other application profiles, such as the one used by the well-known Ocean Biogeographic Information System, (OBIS) ${ }^{8}$. OBIS publishes data on behalf of scientists from governmental agencies, museums, universities, commercial companies, and non-governmental organisations $^{9}$ (OBIS, 2009). The OBIS schema is an extension of the Darwin Core Version 2 standard. When queries are sent out to its distributed data contributors, the OBIS portal and data sets will utilize these elements (fields) to transfer the information needs and results.

\subsubsection{Domain-specific markup languages}

Markup languages have as their starting points the function of revealing the contents inside of a resource. Using a markup language standard, useful elements in a scientific resource such as mathematics formulae, material properties, and chemical compounds are marked up and ready for indexing and retrieval. Figure 2 is an illustration created based on MatML schema ${ }^{10}$. It shows that:

a) The information contained by the "Material" element is compartmentalized into five major elements:

1. "BulkDetails" element contains a description of the bulk material

2. "ComponentDetails" element contains a description of each component of the bulk material (useful for complex materials systems such as composites or welds)

3. "Metadata" element contains descriptions of data found in the document

4. "Graphs" element encodes two-dimensional graphics

5. "Glossary"

b) We can further use the "BulkDetails" element to find out its sub-elements; some of which have their own sub-sub-elements, as shown under "Characterization" as an example: BulkDetails

* Name

* Class

* Subclass

* Specification

* Characterization

- Formula

- ChemicalComposition

- PhaseComposition

- DimensionalDetails

- Notes

* Source

* Form

* ProcessingDetails

* PropertyData

* Notes

${ }^{8}$ OBIS. The Ocean Biogeographic Information System, http://www.iobis.org/.

${ }_{9}^{9}$ OBIS. About the data. The Ocean Biogeographic Information System, http://www.iobis.org/tech/\#_Toc164083855.

${ }^{10}$ MatML Overview. http://www.matml.org/.

Enc. Bibli: R. Eletr. Bibliotecon. Ci. Inf., Florianópolis, n. esp., $2^{\circ}$ sem. 2010. ISSNe 1518-2924. 


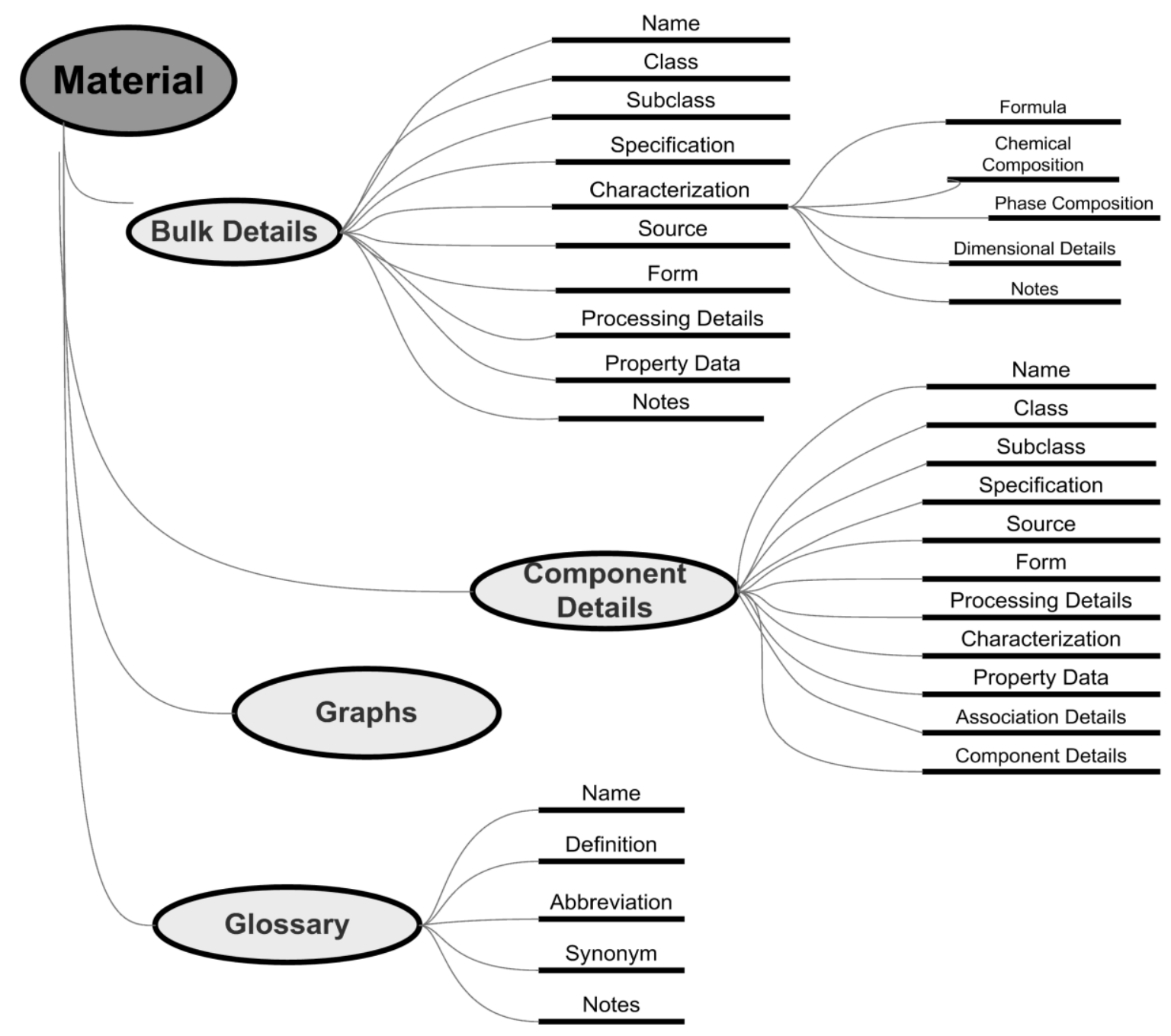

Figure 2 - Illustration of MatML elements, based on MatML Schema ${ }^{11}$

Source: Smith e Zeng (2009, p. 198).

If we take the example of a dissertation in materials science again, using the elements defined by MatML, contents within the dissertation (or in each chapter) are marked up and are easily discoverable according to all these specific properties.

\section{MAXIMIZING THE FUNCTION IN DISCOVERY}

There is no doubt that both the descriptions of an information resource container and its contents are needed in resource discovery for scientific materials. These two approaches are complementary and should be utilized in an integrated method. The following are the proposed methodologies based on a previous experiment ${ }^{12}$ (SHREVE; ZENG, 2003) and continuous studies.

\footnotetext{
${ }^{11}$ SMITH, Terence; ZENG, Marcia Lei. Semantic Tools to Support the Use and Construction of Concept-based Learning Spaces. In: ELearning for Geographers. REES, Philip; MACKAY, Louise; FILL, Karen; DURHAM, Helen (eds.). Hersey, Pennsylvania: Idea Group, 2008, p. 185-203.

${ }^{12}$ Shreve; Zeng, 2003, op. cit.

Enc. Bibli: R. Eletr. Bibliotecon. Ci. Inf., Florianópolis, n. esp., $2^{\text {o }}$ sem. 2010. ISSNe 1518-2924.
} 


\subsection{Extending a metadata schema with a domain-specific category}

In an application profile an additional domain-specific category of elements are appended. Elements in this category are from or based on a markup language standard.

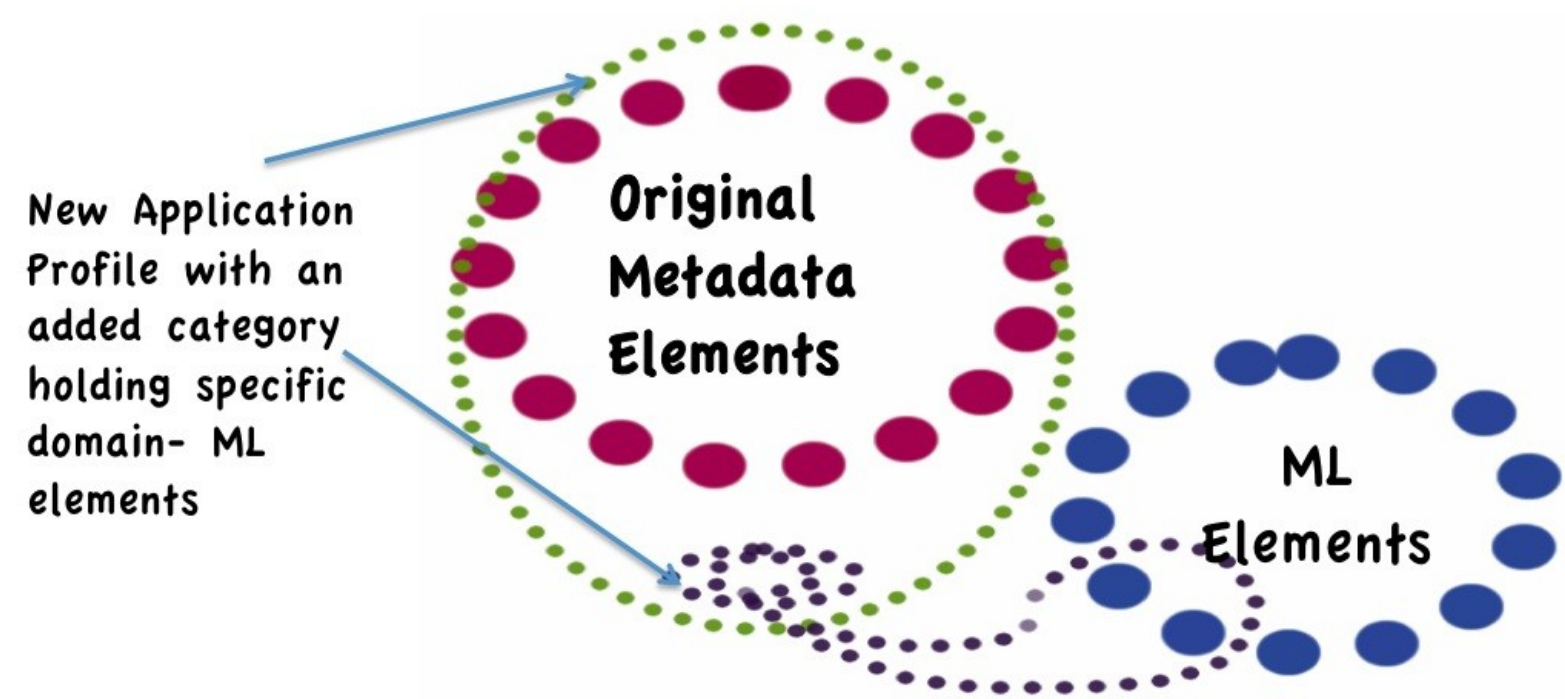

Figure 3 - Illustration of a methodology that extends a metadata schema with a domain-specific category Source: Created by the author.

In the previous section the ADN example showed how subject-oriented categories can be integrated into a metadata framework. In the GREEN project ${ }^{13}$ (SHREVE; ZENG, 2003) LOM application profile, we experimented by extending LOM's nine categories to ten with an added category Materials\}, which contains selected elements that are defined in the MatML DTD or XML schema. For example a document originally would have the LOM metadata description plus those in the \{Materials\} category:

Title: Boundary Element Analysis of Bimaterials Using Anisotropic Elastic Green's Functions Identifier: http://www.boulder.nist.gov/div853/greenfn/pdfiles/jbwshop0.PDF

Taxon: Anisotropic Elastic Solids

Keywords: anisotropic solids, Kelvin solution, copper-nickel system, boundary integral equations, elastic constants, multilayer materials, matrix function .....

Materials:

Bulk material: Copper-nickel multiplayer

Component: Cu-Ni; Co-Cr; Fe-GaAs

Processing: The materials are fabricated by depositing alternating layers of thin-film materials such as $\mathrm{Cu}-\mathrm{Ni}, \mathrm{Co}-\mathrm{Cr}$, and Fe-GaAs.

In this case, it does not matter whether it is LOM or other metadata application profiles, the descriptions for the added category can be completed separately in the workflow. The process is closer to subject indexing, with more domain-specific properties and values. The result is still a surrogate of a resource but it now provides more detailed information about resource content than the original metadata record. This might help a user to decide whether it is worthwhile to obtain and read the resource. 
The decision as to whether the category is mandatory or optional will have an impact on the workflow and workload. If not mandatory, only a selected set of resources would have actually incorporated these elements and provided values in their records. Consequently, the system that provides access to this digital collection should be careful about providing browsing and filtering by materials options because of the incomplete resource set.

\subsection{Using the "relation" element(s) to establish the links to external markup}

In almost all metadata schemas there is usually one or a group of "relation" elements, for example, "dc:relation", "lom:relation", and specifically, relations for administrative: "dct:isVersionOf", "dct:replaces" or for structural relations: "dct:hasPart", "dct:isPartOf", "lom:relation.kind", and "lom:relation.source". Although not exclusively specified, non-literal values are expected to be used with any such element. This means that a related external resource with an identifiable identifier can be connected in this way.

The method is to employ the 'relation' element(s) to link to a record that is generated according to a markup language standard or a whole document in which markup tags are embedded in the full text.

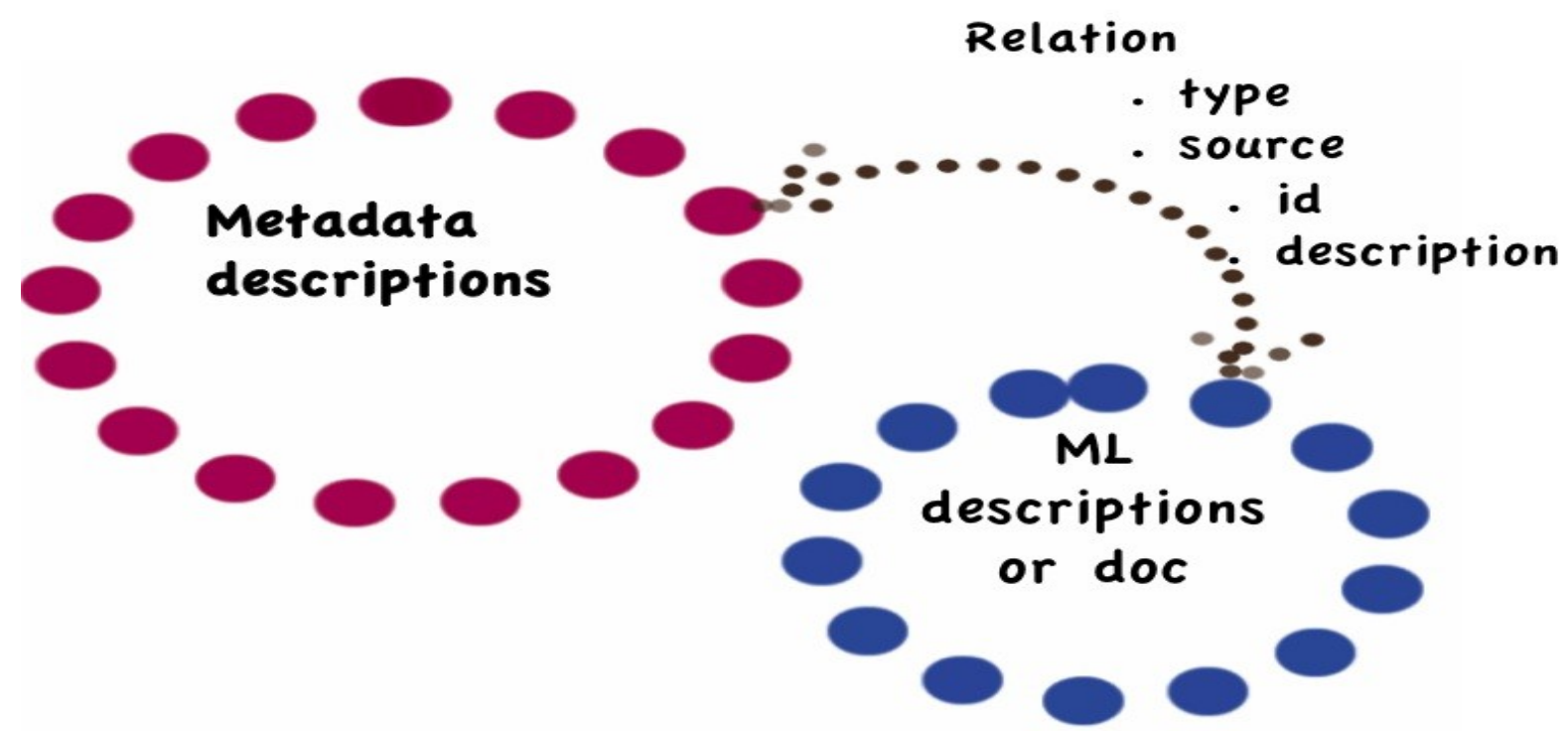

Figure 4 - Illustration of a methodology that uses the "relation" element(s) to establish the links to external markup

Source: Created by the author.

Creating this kind of markup record requires great subject expertise. Embedding markup tags in the whole text is an even more sophisticated process (See examples provided by MatML Website at http://www.matml.org/examples.htm). As a result, the linked records have high values in revealing the contents of an information resource.

Decisions can be made based on an assessment of what contents in the described document should be marked-up. However, the two descriptions should be coordinated at the time the metadata record is created. Otherwise it is doubly time-consuming: one must go back to create the linkages and it has to be verified to ensure that the resource at hand is the one described by the existing record. 


\subsection{Combining metadata and markup descriptions through a third schema}

Similar to putting a puzzle together, different types of metadata elements (descriptive, administrative, technical, use, and preservation) from different schemas, vocabularies, and applications can be interoperably combined. A metadata record (often considered a basic unit in the information professions) should be seen as sets of descriptions. Hence the combination of metadata descriptions should be both reasonable and feasible.

The Metadata Encoding and Transmission Standard (METS) schema "is a standard for encoding descriptive, administrative, and structural metadata concerning objects within a digital library"14. A METS record can contain seven major sections: Header, Structural map, Administrative metadata, Descriptive metadata, Link structure, File section, and Behaviors, as illustrated in Figure 5:

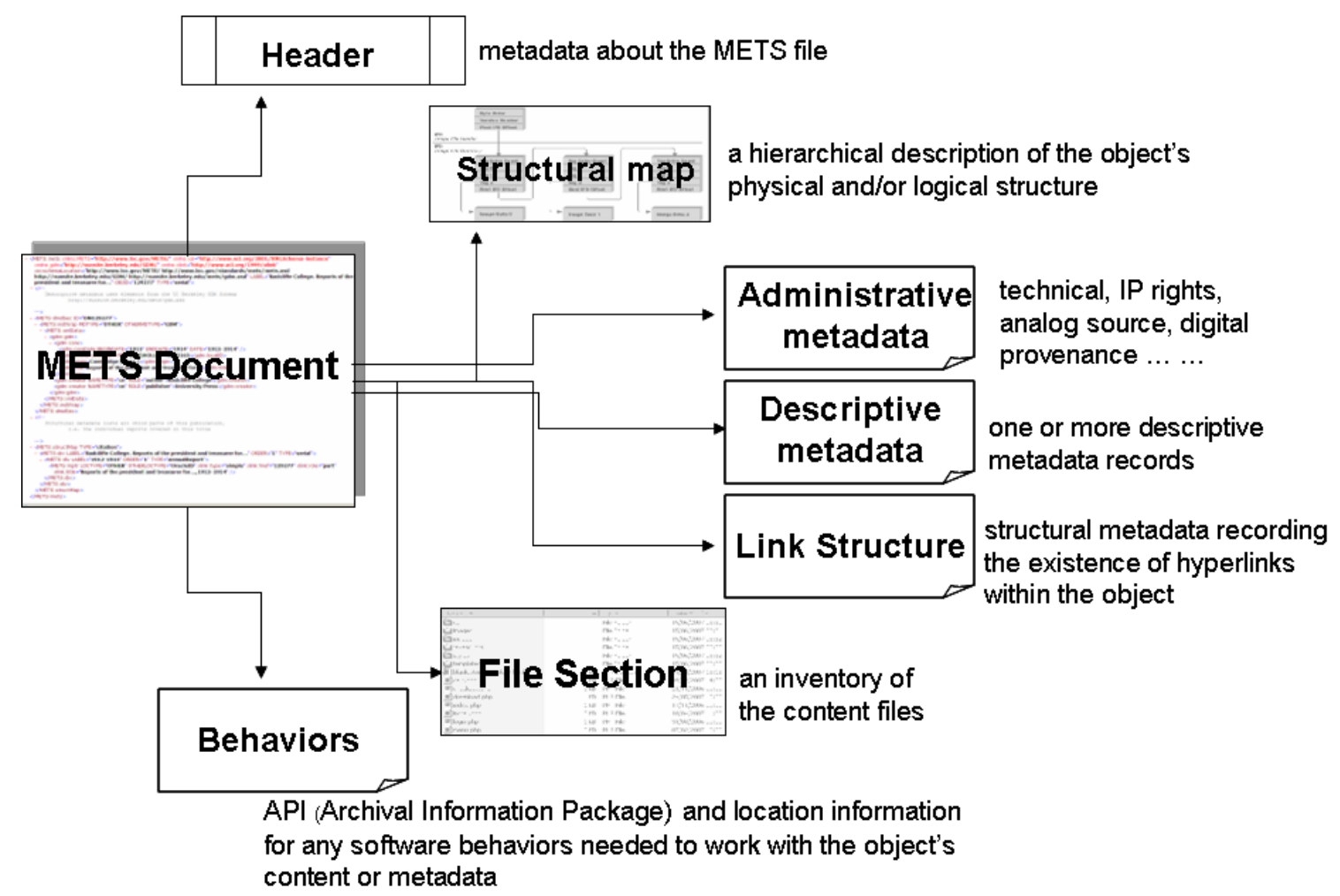

Figure 5 - Illustration of METS components, composite by the author, based on McDonough, 2006: www.loc.gov/standards/premis/ICDAT2006/pages/Slide15_gif.htm ${ }^{15}$.

Source: Reprinted from Zeng and Qin, 2008, p. 200.

Of these seven sections, the descriptive metadata section in a METS record may point to descriptive metadata external to the METS document, or, it may contain internally embedded descriptive metadata. METS allows reuse of the descriptive metadata by either including it in a new record or providing a pointer to the external record. With other sections such as the structural maps and link structure, it is theoretically possible, and achievable, to combine metadata descriptions with markup descriptions (either records or documents). This methodology is illustrated in Figure 6.

\footnotetext{
${ }^{14}$ Metadata Encoding and Transmission Standard (METS). http://www.loc.gov/standards/mets/.

${ }^{15}$ ZENG, Marcia Lei; QIN, Jian. Metadata. New York, NY: Neal-Schuman, 2008.

Enc. Bibli: R. Eletr. Bibliotecon. Ci. Inf., Florianópolis, n. esp., $2^{\circ}$ sem. 2010. ISSNe 1518-2924.
} 


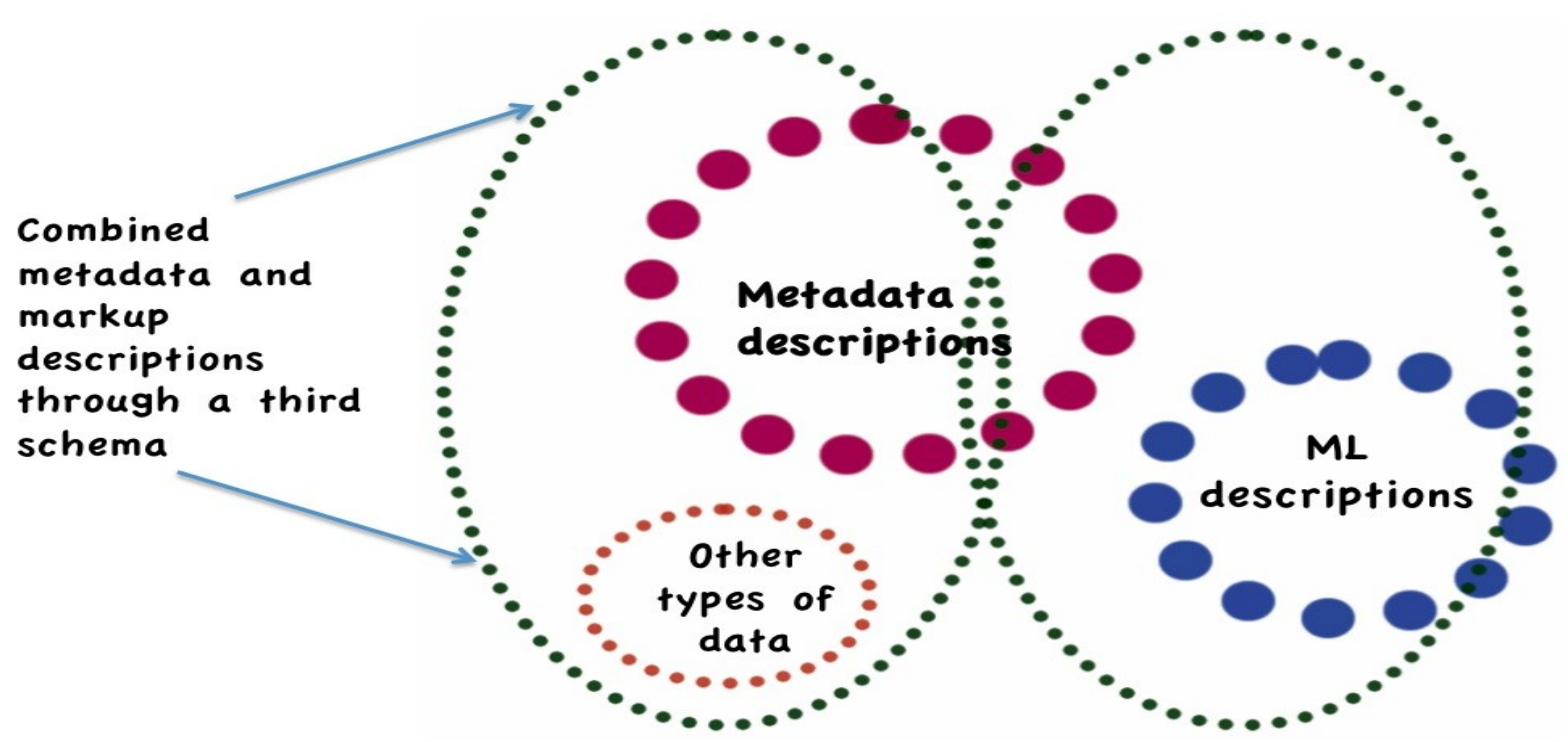

Figure 6 - Illustration of the methodology that combines metadata and markup descriptions through a third schema

Source: Created by the author.

Employing a third schema as a foundation to aggregate descriptions from both metadata description and markup records (or documents) greatly increases consistency, and thus also ensures interoperability. If not using METS, defining a RDF schema for the same purpose can be equally effective. It can be used to create documents that indicate all composition, decomposition, and combination and recombination relations for original or new resources.

In addition to the results of the combination, this approach also enables integrating machineand human-generated descriptions. Existing descriptions can be reused for other appropriate projects. Simultaneously, the quality of metadata can be enhanced through recombinant metadata. Overall, integrated records can be generated for better access and sharing. This approach will require additional effort to plan, test, and organize the workflow; therefore, it is a more complicated process and will involve more parties than those described in Sections 3.1 and 3.2 .

\section{CONCLUSION}

Metadata and markup language standards and applications will move forward, each in their own direction, and facilitate the further discovery of scientific resources. They have expended tremendous effort and generated remarkable results within only the last two decades. Domainspecific markup languages, however, seem to have lagged conceptually in being considered a complementary resource to metadata. Resource level metadata descriptions alone, at today's most common level, cannot create the rich, granular, associative, and recombinant collection that scientists want from a digital collection. Convergence is needed, especially in the areas where metadata and markup efforts are overlapping.

The topics discussed in the paper suggest an ambitious research agenda, particularly in the areas of inter-relationship and interoperability. It is the hope of the author to draw stronger attention from a wider research community in order to find more experimental collaboration opportunities. 


\section{REFERENCES}

ADN Framework Geospatial Overview, 2003. Access: http://www.dlese.org/Metadata/adnitem/geospatial.php.

NISO. Understanding Metadata. Bethesda, MD: NISO Press, 2004. Access:

http://www.niso.org/standards/resources/UnderstandingMetadata.pdf.

OBIS. The Ocean Biogeographic Information System. About the data. 2009. Access: http://www.iobis.org/tech/\#_Toc164083855.

SHREVE, Gregory M.; ZENG, Marcia Lei. Integrating Resource Metadata and Domain Markup in an NSDL Collection. In: DC-2003: Proceedings of the International DCMI Metadata Conference and Workshop, Sept. 28-Oct. 2, 2003, Seattle, Washington, p. 223-229. Access: http://www.siderean.com/dc2003/604_paper62.pdf.

SMITH, Terence; ZENG, Marcia Lei. Semantic Tools to Support the Use and Construction of Concept-based Learning Spaces. In: E-Learning for Geographers. REES, Philip; MACKAY, Louise; FILL, Karen; DURHAM, Helen (eds.). Hersey, Pennsylvania: Idea Group, 2008, p. 185-203.

ZENG, Marcia Lei; QIN, Jian. Metadata. New York, NY: Neal-Schuman, 2008.

\section{Metadata Standards Mentioned in the Paper}

ADN (ADEPT/DLESE/NASA) Metadata Framework. Access:

http://www.dlese.org/Metadata/adn-item/.

Content Standards for Digital Geospatial Metadata (CSDGM). Access:

http://www.fgdc.gov/standards/projects/FGDC-standards-projects/metadata/basemetadata/v2_0698.pdf.

Darwin Core. Access: http://rs.tdwg.org/dwc/.

Dublin Core Metadata Element Set. Access: http://dublincore.org/documents/dces/.

Dublin Core Metadata Terms. Access: http://dublincore.org/documents/dcmi-terms/.

Electronic Theses and Dissertations Metadata Standard (ETD-MS). Access:

http://www.ndltd.org/standards/metadata.

International Standards Organisation. ISO/TS 19115:2003 Geographic information Metadata. Access: http://www.iso.org/iso/catalogue_detail.htm?csnumber=26020.

Learning Object Metadata (LOM). Access: http://ltsc.ieee.org/wg12/index.html.

Metadata Object Description Schema (MODS). Access: http://www.loc.gov/standards/mods/

National Library of Medicine (NLM) Metadata Schema. Access:

http://www.nlm.nih.gov/tsd/cataloging/metafilenew.html

The Ocean Biogeographic Information System (OBIS) schema, version 1.1. Access: http://www.iobis.org/tech/provider/schemadef1.html 


\section{Markup Language Standards Mentioned in the Paper}

Canadian Road Markup Language (for Road Network File). Access:

http://www.ogcnetwork.net/node/225.

Chemical Markup Language (CML). Access: http://cml.sourceforge.net/.

CityGML. Access: http://www.ogcnetwork.net/gml-citygml.

Cyclone Warning Markup Language (CWML). Access:

http://www.ogcnetwork.net/node/397.

Digital Weather Geography Markup Language (dwGML). Access:

http://www.ogcnetwork.net/node/226.

Geography Markup Language (GML). Access: http://www.opengeospatial.org/standards/gml.

GML 3.1.1 Application schema for Earth Observation products. Access:

http://www.ogcnetwork.net/node/380.

GML-Geographic Data Files (GDF-GML). Access: http://www.ogcnetwork.net/node/218.

GPlates Markup Language. Access: http://www.ogcnetwork.net/node/216.

Mathematical Markup Language (MathML). Access: http://www.w3.org/TR/MathML/.

MatML, XML for Materials Property Data. Access: http://www.matml.org/.

Medical Markup Language (MML) Specification 3.0. Access:

http://www.medxml.net/E_mml30/MMLV3Spec.pdf.

SoTerML (Soil and Terrain Markup Language). Access:

http://www.ogcnetwork.net/node/618.

Tsunami Warning Markup Language (TWML) - Draft. Access:

http://www.ogcnetwork.net/node/378.

\section{RESUMO:}

Enquanto os metadados tiveram grande foco em publicações, projetos e iniciativas dos profissionais da informação durante as últimas duas décadas, um número significativo de linguagens de marcação específicas por domínio também se desenvolveram paralelamente a uma taxa equivalente à dos padrões de metadados; mas ainda não recebem atenção comparável. Esse artigo discute as funções desses dois tipos de abordagens na descoberta de recursos científicos e aponta papéis potenciais e complementares por meio de abordagens de interoperabilidade apropriadas.

PALAVRAS-CHAVE: Metadado. Linguagem de marcação. Recurso científico.

Originais recebidos em: 26/07/2010

Aceito para publicação em: 29/09/2010 